\title{
Pandemic products and volatile chemical emissions
}

\author{
Anne Steinemann ${ }^{1,2} \cdot$ Neda Nematollahi ${ }^{1} \cdot$ Behzad Rismanchi $^{1} \cdot$ Nigel Goodman $^{3} \cdot$ Spas D. Kolev $^{4}$
}

Received: 30 July 2020 / Accepted: 17 August 2020 / Published online: 27 August 2020

(C) Springer Nature B.V. 2020

\begin{abstract}
The recent pandemic (COVID-19) has seen a sweeping and surging use of products intended to clean and disinfect, such as air sprays, hand sanitizers, and surface cleaners, many of which contain fragrance. However, exposure to fragranced cleaning products has been associated with adverse effects on human health. Products can emit a range of volatile chemicals, including some classified as hazardous, but relatively few ingredients are disclosed to the public. Thus, relatively little is known about the specific emissions from these products. This study investigates the volatile organic compounds (VOCs) emitted from "pandemic products" that are being used frequently and extensively in society. In addition, among these emissions, this study identifies potentially hazardous compounds, compares so-called green and regular versions of products, and examines whether ingredients are disclosed to the public. Using gas chromatography/mass spectrometry, 26 commonly used pandemic products, including 13 regular and 13 so-called green versions, were analyzed for their volatile emissions. Product types included hand sanitizers, air disinfectants, multipurpose cleaners, and handwashing soap. All products were fragranced. The analyses found the products collectively emitted 399 VOCs with 127 VOCs classified as potentially hazardous. All products emitted potentially hazardous compounds. Comparing regular products and green products, no significant difference was found in the emissions of the most prevalent compounds. Further, among the 399 compounds emitted, only $4 \%$ of all VOCs and $11 \%$ of potentially hazardous VOCs were disclosed on any product label or safety data sheet. This study reveals that pandemic products can generate volatile emissions that could pose risks to health, that could be unrecognized, and that could be reduced, such as by using fragrance-free versions of products.
\end{abstract}

Keywords Pandemic $\cdot$ Coronavirus $\cdot$ Fragranced consumer products $\cdot$ Volatile organic compounds $\cdot$ Emissions $\cdot$ Cleaning . Disinfectants $\cdot$ Hand sanitizers

Electronic supplementary material The online version of this article (https://doi.org/10.1007/s11869-020-00912-9) contains supplementary material, which is available to authorized users.

Anne Steinemann

anne.steinemann@unimelb.edu.au

1 Department of Infrastructure Engineering, Melbourne School of Engineering, The University of Melbourne, Parkville, Victoria 3010, Australia

2 College of Science and Engineering, James Cook University, Townsville, Queensland 4814, Australia

3 School of Property Construction and Project Management, RMIT University, Melbourne, VIC 3000, Australia

4 School of Chemistry, The University of Melbourne, Parkville, Victoria 3010, Australia

\section{Introduction}

Cleaning and disinfection products are common in society, especially with increased frequency and extent of use during the coronavirus pandemic. The preponderant use of productssuch as air fresheners and disinfectants, hand sanitizers and soaps, and multipurpose surface cleaners - appears to focus on the virus and not necessarily emissions, with the assumption that more use is better. Consequently, chemical exposures from products can be increasing across the population. However, and paradoxically, products intended to reduce risks to health may actually be posing risks to health, albeit in other ways. Important questions arise, such as the following: What is actually emitted from the products? Do any chemicals pose possible hazards? Are so-called green or natural products any different? Are product ingredients fully disclosed to the public?

This study investigates emissions from a range of cleaning and disinfectant products that have been commonly used during the pandemic, which this article terms "pandemic products." The study pursues four main objectives: (a) to analyze the volatile organic compounds (VOCs) emitted from a set of 
typical fragranced pandemic products, (b) to identify the compounds classified as potentially hazardous, (c) to compare emissions between regular and so-called green versions of products, and (d) to assess whether compounds emitted are disclosed on product labels or safety data sheets. Results from this study can provide a scientific foundation to understand emissions from the use of pandemics products, and ways to reduce risks.

Cleaning and disinfection products have a history of associations with effects on health. Nazaroff and Weschler (2004) synthesize evidence of adverse health outcomes linked to chemical exposures from the use of cleaning products and air fresheners. In addition, use of fragranced cleaning products and air disinfectants has been associated with migraine headaches (e.g., SilvaNéto et al. 2014; Steinemann and Nematollahi 2020), asthma attacks and exacerbations (e.g., Zock et al. 2007; Weinberg et al. 2017; Steinemann and Goodman 2019), childhood wheeze (e.g., Parks et al., 2020; Sherriff et al. 2005), and additional health problems related to neurological, gastrointestinal, respiratory, dermatological, and immune systems (e.g., Steinemann 2019a).

In recent work, nationally representative population-based studies, across the United States, Australia, the United Kingdom, and Sweden, found that $32.2 \%$ of the general population on average $(34.7 \%, 33.0 \%, 27.8 \%, 33.1 \%$, respectively) report health problems when exposed to fragranced consumer products, including air fresheners, deodorizers, hand soaps, hand sanitizers, all-purpose cleaners, and disinfectants (Steinemann 2018a, b, 2017a, 2016).

Further, across these four countries, $17.4 \%$ of the general population, and $36.7 \%$ of asthmatics, report health problems when exposed to air fresheners and deodorizers. Also, 15.7\% of the general population, and $32.9 \%$ of asthmatics, report health problems from being in a room after it has been cleaned by fragranced products (Steinemann 2019a, Steinemann and Goodman 2019).

In prior chemical analyses and comparisons of fragranced and fragrance-free cleaning products (Steinemann 2015; Nematollahi et al. 2019), all of the fragranced products emitted terpenes (e.g., limonene, alpha-pinene, beta-pinene), but none of the fragrance-free products emitted terpenes. Terpenes can act as both primary pollutants as well as react with ozone to generate a range of secondary pollutants, such as formaldehyde.

\section{Methods}

For this study, 26 common cleaning and disinfectant products, widely used and sold in two countries (the United States and Australia), were randomly selected and analyzed for their emissions. Product types were hand sanitizers, air disinfectants, multipurpose cleaners and disinfectants, and handwashing soap; each of the products was fragranced (see Table 1).

The products selected include both "green" and "regular" versions. Herein, the term "green" refers to products with the claim of being "green" or related terms, such as "natural" or "organic." The term "regular" refers to products other than those in the "green" category.

Criteria for selection as a "pandemic product" were (i) a government issued public health recommendation for a product type to be used more frequently and extensively for purposes against the coronavirus, (ii) a government issued approval for a specific product to be used for purposes against the coronavirus, or (iii) both.

To determine the volatile ingredients, headspace gas chromatography/mass spectrometry (GC/MS) was used to analyze the VOCs emitted from the products. The chromatogram for each product was scanned to identify the highest concentration VOCs (top 20 peaks). Compound identification was based on the mass spectral library of the National Institute of Standards and Technology NIST Version 2.0 (see Nematollahi et al. 2018; Steinemann et al. 2011 for additional details on the analytic methods). Chromatographic data for each product, as reported in supplementary tables of Nematollahi et al. (2019) and Steinemann (2015), were reanalyzed for the purposes of this study, including new analyses of VOC prevalences, hazardous compound classifications, comparisons of regular and green products, ingredient disclosures, and product claims related to the pandemic.

Potentially hazardous VOCs were identified according to classifications of (i) hazardous air pollutants (HAPs), United States Environmental Protection Agency (EPA 2017), including carcinogenic HAPs (EPA 2018), (ii) Hazardous Chemical Information System (HCIS), Safe Work Australia (SWA 2020), and (iii) asthmagens, Association of Occupational and Environmental Clinics (AOEC 2020). This analysis was performed to identify ingredients that are classified as potentially hazardous under one or more of these criteria. However, this analysis does not imply an evaluation of product safety or risks.

Table 1 Types of tested products

\begin{tabular}{llllll}
\hline & Hand sanitizer & Air disinfectant & $\begin{array}{l}\text { Multipurpose cleaners } \\
\text { and disinfectants }\end{array}$ & Handwashing soap & Total \\
\hline Regular & 1 & 3 & 5 & 4 & 13 \\
Green & 1 & 2 & 6 & 4 & 13 \\
Total & 2 & 5 & 11 & 8 & 26 \\
\hline
\end{tabular}


It also does not imply that these VOCs are the only potentially hazardous compounds emitted or generated from the products.

\section{Results}

\section{VOCs emitted and most prevalent VOCs}

A summary of VOCs emitted across the 26 cleaning products, both regular and green, is provided in Table 2. In this paper, the term "VOC occurrences" refers to the number of individual VOCs emitted from the products, such that each VOC occurrence represents a single volatile ingredient in a single product. The term "VOC identities" refers to the number of distinctly named VOCs emitted from the products, such that each VOC identity represents a compound, according to name and CAS number, that occurs in one or more of the products.

Across the 26 cleaning products, 399 VOCs were emitted (occurrences), representing 172 VOCs identities. The most prevalent VOCs (in at least $40 \%$ of all products) were limonene, ethanol, alpha-pinene, beta-pinene, and acetaldehyde (Table 3). In both "regular" and "green" products, the most prevalent VOC was limonene. Data on emissions from each specific product, as well as the most prevalent VOCs across the products, are provided in Supplementary Tables 1 and 2.

\section{Potentially hazardous emissions}

For the 399 VOCs (occurrences) emitted collectively from the 26 products, 127 VOCs are classified as potentially hazardous, representing approximately $30 \%$ of all VOC ingredients. All products emitted between 1 and 4 VOCs classified as potentially hazardous.

For the 172 VOCs (identities) emitted across the 26 products, 46 VOCs are classified as potentially hazardous. The most prevalent potentially hazardous VOCs (in at least $25 \%$ of all cleaning products) were limonene, ethanol, acetaldehyde, 3-carene, and methanol (Table 4).

\section{Comparison of VOCs emitted from regular and green products}

Among the most prevalent VOCs, no significant difference was found in the VOC identities and occurrences between the regular and green products ( $p=0.11, t$ test). In addition, among the most prevalent potentially hazardous VOCs, no significant difference was found in VOC identities and occurrences between regular and green products ( $p=0.17, t$ test). This comparison followed the convention of previously published work (e.g., Steinemann 2015, Nematollahi et al. 2019) that analyzed and compared regular and green products.

\section{Comparison of VOCs emitted and ingredients disclosed}

Among the 399 VOCs emitted from the products, only 16 were listed on any product label or safety data sheet. In addition, among the 127 VOCs classified as potentially hazardous emitted from the products, only 14 were listed on any product label or safety data sheet (Table 2). Thus, only $4 \%$ of all VOCs, and $11 \%$ of the potentially hazardous VOCs, were disclosed to the public on product labels or safety data sheets.

\section{Discussion}

This study found that fragranced pandemic products of all types, including both regular and green versions, emit numerous volatile chemicals, some of which are classified as hazardous, and few of which are disclosed to the public. Thus, chemical emissions and associated risks may be largely unrecognized. Results are especially concerning given that chemical exposures may be involuntary, and affect vulnerable populations such as children, the elderly, and individuals in institutions and care facilities.

Our findings are consistent with prior studies of fragranced cleaning products and air fresheners (Steinemann 2015, 2017b, 2019a, b; Steinemann et al. 2011; Nematollahi et al. 2019, 2018; Uhde and Schulz 2015) as follows. First, terpenes

Table 2 VOCs emitted from products*

\begin{tabular}{|c|c|c|c|c|c|}
\hline \multirow[b]{2}{*}{ Type } & \multirow[b]{2}{*}{ Number of products } & \multicolumn{2}{|l|}{ Emitted } & \multicolumn{2}{|c|}{ Listed (on product label or safety data sheet) } \\
\hline & & All VOCs & Potentially hazardous VOCs & All VOCs & $\begin{array}{l}\text { Potentially Hazardous } \\
\text { VOCs }\end{array}$ \\
\hline Regular & 13 & 211 occurrences 122 identities & 61 occurrences 35 identities & 4 occurrences 3 identities & 4 occurrences 3 identities \\
\hline Green & 13 & 188 occurrences 96 identities & 58 occurrences 24 identities & 7 occurrences 5 identities & 5 occurrences 3 identities \\
\hline Total & 26 & 399 occurrences 172 identities & 127 occurrences 46 identities & 16 occurrences 7 identities & 14 occurrences 5 identities \\
\hline
\end{tabular}

*"VOC occurrences" refers to the number of individual VOCs emitted from the products

"VOC identities" refers to the number of distinctly named VOCs emitted from one or more of the products 
Table 3 Most prevalent VOCs emitted from products

\begin{tabular}{|c|c|c|c|c|}
\hline \multirow[t]{2}{*}{ Compound } & \multirow[t]{2}{*}{ CAS \# } & \multicolumn{3}{|c|}{ Prevalence (\# of products) } \\
\hline & & Total $(n=26)$ & Regular $(n=13)$ & Green $(n=13)$ \\
\hline \multicolumn{5}{|l|}{ All products $(n=26)$} \\
\hline Limonene* & $138-86-3$ & 21 & 10 & 11 \\
\hline Ethanol* & $64-17-5$ & 17 & 7 & 10 \\
\hline alpha-Pinene & $80-56-8$ & 13 & 7 & 6 \\
\hline beta-Pinene & $127-91-3$ & 12 & 8 & 4 \\
\hline Acetaldehyde* & $75-07-0$ & 11 & 4 & 7 \\
\hline Eucalyptol & $470-82-6$ & 11 & 4 & 7 \\
\hline gamma-Terpinene & $99-85-4$ & 11 & 5 & 6 \\
\hline beta-Myrcene & $123-35-3$ & 10 & 1 & 9 \\
\hline beta-trans-Ocimene & $3779-61-1$ & 10 & 3 & 7 \\
\hline Camphene & $79-92-5$ & 10 & 5 & 5 \\
\hline 3-Carene* & $13,466-78-9$ & 8 & 4 & 4 \\
\hline beta-Phellandrene & $555-10-2$ & 8 & 5 & 3 \\
\hline Linalool & $78-70-6$ & 8 & 4 & 4 \\
\hline alpha-Phellandrene & $99-83-2$ & 7 & 3 & 4 \\
\hline Methanol* & $67-56-1$ & 7 & 3 & 4 \\
\hline \multicolumn{5}{|l|}{ Regular products $(n=13)$} \\
\hline Limonene* & $138-86-3$ & & 10 & \\
\hline beta-Pinene & $127-91-3$ & & 8 & \\
\hline Ethanol* & $64-17-5$ & & 7 & \\
\hline alpha-Pinene & $80-56-8$ & & 7 & \\
\hline gamma-Terpinene & $99-85-4$ & & 5 & \\
\hline Camphene & $79-92-5$ & & 5 & \\
\hline beta-Phellandrene & $555-10-2$ & & 5 & \\
\hline Acetaldehyde* & $75-07-0$ & & 4 & \\
\hline Eucalyptol & $470-82-6$ & & 4 & \\
\hline 3-Carene* & $13,466-78-9$ & & 4 & \\
\hline Linalool & $78-70-6$ & & 4 & \\
\hline 6-Methyl-5-hepten-2-one & $110-93-0$ & & 4 & \\
\hline o-Cymene & $527-84-4$ & & 4 & \\
\hline Butane* & $106-97-8$ & & 4 & \\
\hline alpha-Terpinene & $99-86-5$ & & 4 & \\
\hline \multicolumn{5}{|l|}{ Green products $(n=13)$} \\
\hline Limonene* & $138-86-3$ & & & 11 \\
\hline Ethanol* & $64-17-5$ & & & 10 \\
\hline beta-Myrcene & $123-35-3$ & & & 9 \\
\hline Acetaldehyde* & $75-07-0$ & & & 7 \\
\hline Eucalyptol & $470-82-6$ & & & 7 \\
\hline beta-trans-Ocimene & $3779-61-1$ & & & 7 \\
\hline alpha-Pinene & $80-56-8$ & & & 6 \\
\hline gamma-Terpinene & $99-85-4$ & & & 6 \\
\hline Camphene & $79-92-5$ & & & 5 \\
\hline beta-Pinene & $127-91-3$ & & & 4 \\
\hline 3-Carene* & $13,466-78-9$ & & & 4 \\
\hline Linalool & $78-70-6$ & & & 4 \\
\hline alpha-Phellandrene & $99-83-2$ & & & 4 \\
\hline Methanol* & $67-56-1$ & & & 4 \\
\hline Acetone* & $67-64-1$ & & & 4 \\
\hline
\end{tabular}

*Classified as potentially hazardous

(e.g., limonene) were the most commonly emitted ingredients. Second, all types of products, even green versions, emitted potentially hazardous VOCs. Third, no significant difference was found in emissions between regular and green products. Fourth, across the studies, fewer than $10 \%$ of volatile ingredients were disclosed to the public on product labels, safety data sheets, websites, or elsewhere.
However, this lack of full ingredient disclosure is permissible. Cleaning products are not required to disclose all of their specific ingredients. Further, a "fragrance" in a product is also exempted from full ingredient disclosure, even though a fragrance is typically a complex mixture of dozens of chemicals. Although products regulated as drugs or cosmetics need to list 
Table 4 Potentially hazardous VOCs emitted from the products

\begin{tabular}{|c|c|c|c|c|c|c|c|}
\hline \multirow[t]{2}{*}{ Compound } & \multirow[t]{2}{*}{ CAS \# } & \multicolumn{3}{|c|}{ Prevalence (\# of products) } & \multirow[t]{2}{*}{ HAPs } & \multirow[t]{2}{*}{ SWA } & \multirow[t]{2}{*}{ Asthmagens } \\
\hline & & Total $(n=26)$ & Regular $(n=13)$ & Green $(n=13)$ & & & \\
\hline Limonene & $138-86-3$ & 21 & 10 & 11 & & $\checkmark$ & \\
\hline Ethanol & $64-17-5$ & 17 & 7 & 10 & & $\checkmark$ & \\
\hline Acetaldehyde** & $75-07-0$ & 11 & 4 & 7 & $\checkmark$ & $\checkmark$ & \\
\hline 3-Carene & $13,466-78-9$ & 8 & 4 & 4 & & & $\checkmark$ \\
\hline Methanol & $67-56-1$ & 7 & 3 & 4 & $\checkmark$ & $\checkmark$ & \\
\hline Acetone & $67-64-1$ & 5 & 1 & 4 & & $\checkmark$ & \\
\hline Butane & $106-97-8$ & 5 & 4 & 1 & & $\checkmark$ & \\
\hline 1-Octanol & $111-87-5$ & 3 & 0 & 3 & & $\checkmark$ & \\
\hline Cyclohexane & $110-82-7$ & 3 & 2 & 1 & & $\checkmark$ & \\
\hline Ethyl acetate & $141-78-6$ & 3 & 2 & 1 & & $\checkmark$ & \\
\hline Pentane & $109-66-0$ & 3 & 1 & 2 & & $\checkmark$ & \\
\hline (E)-citral & $141-27-5$ & 2 & 1 & 1 & & $\checkmark$ & \\
\hline 2-Methyl-2-propanol & $75-65-0$ & 2 & 2 & 0 & & $\checkmark$ & \\
\hline Acetaldehyde diethyl acetal & $105-57-7$ & 2 & 1 & 1 & & $\checkmark$ & \\
\hline beta-Citral & $106-26-3$ & 2 & 1 & 1 & & $\checkmark$ & \\
\hline Butanone & $78-93-3$ & 2 & 1 & 1 & & $\checkmark$ & \\
\hline Isopropyl alcohol & $67-63-0$ & 2 & 1 & 1 & & $\checkmark$ & \\
\hline 1,1-Dichloroethylene & $75-35-4$ & 1 & 1 & 0 & $\checkmark$ & $\checkmark$ & \\
\hline 2,4-Dimethylpentane & $108-08-7$ & 1 & 1 & 0 & & $\checkmark$ & \\
\hline 2-Chlorotoluene & $95-49-8$ & 1 & 0 & 1 & & $\checkmark$ & \\
\hline 2-Methyl-1-propene & $115-11-7$ & 1 & 1 & 0 & & $\checkmark$ & \\
\hline 3-Methylhexane & $589-34-4$ & 1 & 0 & 1 & & $\checkmark$ & \\
\hline 5-Methylheptan-3-one & $541-85-5$ & 1 & 1 & 0 & & $\checkmark$ & \\
\hline Allyl alcohol & $107-18-6$ & 1 & 1 & 0 & & $\checkmark$ & \\
\hline Benzaldehyde & $100-52-7$ & 1 & 0 & 1 & & $\checkmark$ & \\
\hline Benzyl alcohol & $100-51-6$ & 1 & 0 & 1 & & $\checkmark$ & \\
\hline Butyraldehyde & $123-72-8$ & 1 & 0 & 1 & & $\checkmark$ & \\
\hline Carbon tetrachloride** & $56-23-5$ & 1 & 1 & 0 & $\checkmark$ & $\checkmark$ & \\
\hline Chloroform** & $67-66-3$ & 1 & 1 & 0 & $\checkmark$ & $\checkmark$ & \\
\hline Citral & $5392-40-5$ & 1 & 0 & 1 & & $\checkmark$ & \\
\hline E-2-butene & $624-64-6$ & 1 & 1 & 0 & & $\checkmark$ & \\
\hline Ethyl formate & $109-94-4$ & 1 & 0 & 1 & & $\checkmark$ & \\
\hline Heptan-4-one & $123-19-3$ & 1 & 1 & 0 & & $\checkmark$ & \\
\hline Heptane & $142-82-5$ & 1 & 1 & 0 & & $\checkmark$ & \\
\hline Hexane & $110-54-3$ & 1 & 1 & 0 & $\checkmark$ & $\checkmark$ & \\
\hline Isoamyl acetate & $123-92-2$ & 1 & 1 & 0 & & $\checkmark$ & \\
\hline Isobutane & $75-28-5$ & 1 & 1 & 0 & & $\checkmark$ & \\
\hline Methyl acetate & $79-20-9$ & 1 & 0 & 1 & & $\checkmark$ & \\
\hline Methyl isobutyl ketone & $108-10-1$ & 1 & 0 & 1 & $\checkmark$ & $\checkmark$ & \\
\hline $\mathrm{N}, \mathrm{N}$-dimethylacetamide & $127-19-5$ & 1 & 1 & 0 & & $\checkmark$ & \\
\hline Octane & $111-65-9$ & 1 & 1 & 0 & & $\checkmark$ & \\
\hline Propane & $74-98-6$ & 1 & 1 & 0 & & $\checkmark$ & \\
\hline Propylene glycol butyl ether & $5131-66-8$ & 1 & 1 & 0 & & $\checkmark$ & \\
\hline Styrene** & $100-42-5$ & 1 & 1 & 0 & $\checkmark$ & $\checkmark$ & $\checkmark$ \\
\hline Tetracarbonylnickel & $13,463-39-3$ & 1 & 1 & 0 & & $\checkmark$ & $\checkmark$ \\
\hline Toluene & $108-88-3$ & 1 & 1 & 0 & $\checkmark$ & $\checkmark$ & \\
\hline
\end{tabular}

HAPs, Hazardous Air Pollutants (HAPs), United States Environmental Protection Agency (EPA 2017),

**Classified as possibly carcinogenic (2B) (EPA 2018)

SWA, Hazardous Chemical Information System (HCIS), Safe Work Australia (SWA 2020)

Asthmagens, Association of Occupational and Environmental Clinics (AOEC 2020)

ingredients, the general term "fragrance" may be listed, instead of specific compounds (see Steinemann 2009; Lunny et al. 2017).

Terpenes are characteristic of fragranced consumer products. In comparisons of fragranced and fragrance-free versions of products, terpenes are the most prevalent compounds in fragranced products, but they are absent in fragrance-free products (Steinemann 2015; Nematollahi et al. 2019). Terpenes are not only primary pollutants, but they also generate a range of secondary pollutants. Thus, choosing products without fragrance could reduce exposures to terpenes and other fragrance compounds, which can include potentially hazardous air pollutants 
and allergens. To note, unscented products are not necessarily fragrance-free, as they can contain fragrance compounds to cover the scent (Steinemann 2019a).

Limitations of the study include the following. The GC/MS headspace analysis identified volatile ingredients that are directly emitted from the product without interactions with ambient air. Thus, the analysis would not have captured a range of secondary pollutants, such as through terpene-ozone interactions, that could contribute to product risks. The study also focused on volatile organic compounds, and products can contain other classes of chemicals, such as semivolatile organic compounds. The GC/MS analysis examined emissions from a single product, whereas emissions from multiple products used together could generate chemical reactions that pose additional risks. Finally, while the study identified specific compounds as well as broader public health issues, the analysis was not intended as a quantification of risks from product use.

Results from the study lead to a question: Are there alternative products that could provide equivalent functionality against the virus but without emissions that may be problematic for health? Given that fragranced cleaning products have been associated with reports of health problems, and that fragrance in product is added for aesthetics, fragrance-free products could offer reasonable alternatives.

\section{Conclusions}

This study provides findings on the VOCs emitted by 26 products frequently and extensively used during the pandemic. The analysis found 399 VOC ingredients, with 127 VOCs classified as potentially hazardous, emitted from the products. Limonene was the most commonly emitted compound, found in $80 \%$ of products. Emissions of the most prevalent potentially hazardous VOCs from regular and green fragranced products were not significantly different. Only $4 \%$ of all VOCs and $11 \%$ of potentially hazardous VOCs were listed on any product label. Results of this study can help to improve awareness about emissions from pandemic products, and provide a foundation for understanding and reducing risks of product use.

Acknowledgments We gratefully acknowledge the supporters of this study: the Clean Air and Urban Landscapes Hub funded by the Australian Government's National Environmental Science Program; and the Commonwealth Scientific and Industrial Research Organisation (CSIRO). We thank Justine Weinberg, Public Health Institute, contractor to Occupational Health Branch, California Department of Public Health, and Jennifer Flattery, Occupational Health Branch, California Department of Public Health, USA, for their very thoughtful review and contributions. We also thank Ian C. MacGregor of Battelle in Columbus, OH, USA, for his excellent work on the analysis of the United States products. Finally, we deeply appreciate the comments from the anonymous reviewers of this paper.

\section{References}

(AOEC) Association of Occupational and Environmental Clinics (2020) Exposure Code List. Asthmagens. http://www.aoecdata.org/. Accessed 25 April 2020

(EPA) Environmental Protection Agency (2017) Initial list of hazardous air pollutants with modifications. https://www.epa.gov/haps/initiallist-hazardous-air-pollutants-modifications, Accessed 25 April 2020

(EPA) Environmental Protection Agency (2018) Prioritized chronic doseresponse values. Weight of evidence for carcinogenicity. https:// www.epa.gov/sites/production/files/2014-05/documents/table1.pdf. Accessed 25 April 2020

Lunny S, Nelson R, Steinemann A (2017) Something in the air but not on the label: a call for increased regulatory ingredient disclosure for fragranced consumer products. Univ New SWL J 40(4):1366-1391

Nazaroff WW, Weschler CJ (2004) Cleaning products and air fresheners: exposure to primary and secondary air pollutants. Atmos Environ 38(18):2841-2865

Nematollahi N, Doronila A, Mornane P, Duan A, Kolev SD, Steinemann A (2018) Volatile chemical emissions from fragranced baby products. Air Qual Atmos Health 11(7):785-790

Nematollahi N, Kolev S, Steinemann A (2019) Volatile chemical emissions from 134 common consumer products. Air Qual Atmos Health 12(11):1259-1265

Parks J, McCandless L, Dharma C, Brook J, Turvey SE, Mandhane P, Becker AB, Kozyrskyj AL, Azad MB, Moraes TJ, Lefebvre DL (2020) Association of use of cleaning products with respiratory health in a Canadian birth cohort. CMAJ 192(7):E154-E161

Safe Work Australia (SWA) (2020) Hazardous Chemical Information System (HCIS). Search Hazardous Chemicals. http://hcis. safeworkaustralia.gov.au/HazardousChemical. Accessed June 2020

Sherriff A, Farrow A, Golding J, Henderson J (2005) Frequent use of chemical household products is associated with persistent wheezing in pre-school age children. Thorax 60(1):45-49

Silva-Néto RP, Peres MFP, Valença MM (2014) Odorant substances that trigger headaches in migraine patients. Cephalalgia 34(1):14-21

Steinemann AC (2009) Fragranced consumer products and undisclosed ingredients. Environ Impact Assess Rev 29(1):32-38

Steinemann A (2015) Volatile emissions from common consumer products. Air Qual Atmos Health 8(3):273-281

Steinemann A (2016) Fragranced consumer products: exposures and effects from emissions. Air Qual Atmos Health 9(8):861-866

Steinemann A (2017a) Health and societal effects from fragranced consumer products. Prev Med Rep 5:45-47

Steinemann A (2017b) Ten questions concerning air fresheners and indoor built environments. Build Environ 111:279-284

Steinemann A (2018a) Exposures and effects from fragranced consumer products in Sweden. Air Qual Atmos Health 11(5):485-491

Steinemann A (2018b) Fragranced consumer products: sources of emissions, exposures, and health effects in the United Kingdom. Air Qual Atmos Health 11(3):253-258

Steinemann A (2019a) International prevalence of fragrance sensitivity. Air Qual Atmos Health 12(8):891-897

Steinemann A (2019b) Ten questions concerning fragrance-free policies and indoor environments. Build Environ 159:1-8

Steinemann A, Goodman N (2019) Fragranced consumer products and effects on asthmatics: an international population-based study. Air Qual Atmos Health 12(6):643-649

Steinemann A, Nematollahi N (2020) Migraine headaches and fragranced consumer products: an international population-based study. Air quality, atmosphere and health (07 March). Air quality, atmosphere and health (07 March)

Steinemann AC, MacGregor IC, Gordon SM, Gallagher LG, Davis AL, Ribeiro DS, Wallace LA (2011) Fragranced consumer products: 
chemicals emitted, ingredients unlisted. Environ Impact Assess Rev 31(3):328-333

Uhde E, Schulz N (2015) Impact of room fragrance products on indoor air quality. Atmos Environ 106:492-502

Weinberg JL, Flattery J, Harrison R (2017) Fragrances and work-related asthma-California surveillance data, 1993-2012. J Asthma 54(10): $1041-1050$
Zock JP, Plana E, Jarvis D, Antó JM, Kromhout H, Kennedy SM, Künzli N, Villani S, Olivieri M, Torén K, Radon K (2007) The use of household cleaning sprays and adult asthma: an international longitudinal study. Am J Respir Crit Care Med 176(8):735-741

Publisher's note Springer Nature remains neutral with regard to jurisdictional claims in published maps and institutional affiliations. 